\title{
Translation of Names and Comparison of Addressing between Chinese and English from the Intercultural Perspective
}

\author{
Xueqing Wang \\ Department of Fundamental Course, Zhenjiang Watercraft College of PLA, Zhenjiang, China \\ Email: richerwang1980@yahoo.com.cn
}

\begin{abstract}
It is self-evident that to communicate, we must first know the participants' names, or successful communication will be impossible. Names not only symbolize identities, but also denote special significance such as the great expectation from the parents. It is absolutely impolite and embarrassing to make mistakes in regard to others' names. Therefore, it is of staggering significance in communication, especially in intercultural one. With the deepening project of reform and opening up to the outside world, frequent intercultural communications take place. Because the structure of people's names in English-speaking countries is different from ours, it is extremely important to correctly translate foreign names and name foreigners. Only when we are aware of the differences can we carry out smooth intercultural communication. In this article, I will analyze these phenomena.
\end{abstract}

Index Terms - translation, names, addressing, English, Chinese

\section{INTRODUCTION}

There have been lots of fervent discussions on translation of names. In regard to the translation of names from Chinese into English, Chinese phonetic system has been used since 1978. But in fact, many overseas Chinese students, Chinese visiting scholars and people living in Hong Kong SAR, Macau SAR and Taiwan province conduct their own practices. Some claim to observe the English habit, i.e., given name first, family name second. Some suggest sticking to the Chinese way, i.e., family name first, leaving the given name to follow. Some say it is neither suitable nor scientific to employ Chinese phonetic system when translating Chinese names. They advise that Chinese should acquire English names in replacement of Chinese names when necessary.

\section{ENGLISH AND CHINESE NAMES IN INTERCULTURAL COMMUNICATION}

\section{A. Differences between English and Chinese names}

Names are part of language, which belongs to culture. Therefore, different factors concerning names reflect differences among cultures in a certain degree. First and foremost, phonetic forms of names in different cultures differ notably. Second, the number of syllables in names differs from culture to culture.

When listing the differences between English and Chinese names specifically, we can cite a legion of examples. For instance, there are more family names in English, but more given names in Chinese. And we Chinese have family name and given name, whereas westerners often have given name, middle name and family name. Furthermore, in linear arrangement of name, we Chinese put family name at the first place, then given name, while in western countries, they do this in a reversed order.

Although names are symbols of humans, they also contain profound meanings. In Chinese and other oriental cultures, choosing proper words to name a baby is an arduous task, for Chinese people believe names are closely related to their destinies. Let's take one name comprising three characters for example. The first character is family name. The middle one reflects his position in family hierarchy. The last character is the given name. Sometimes, people may rack their brains in order to give the new-born good Chinese names. Generally, Chinese names are simple, including two or three characters. English names usually possess a long array of letter, but they are interesting in that one's gender can easily be identified according to his or her names.

\section{B. Dealing with the Differences during Translation}

Now that names are essential to smooth intercultural communication and there are so many characteristics about names, how can we deal with it in intercultural communication?

First, we must be clear that translation of names is restricted by the language used in communication. Roughly speaking, one certain language should first be designated for the communication, and then names of both sides should be translated with words having similar pronunciation in the designated language. But minor adjustments are necessary if differences between the two languages are almost unable to bridge. For example, we translate "smith", which is 
composed of one syllabus, into “史密斯”, which contains three syllables. And Chinese name “任志坚” is turned into Ren Zhijian based on Chinese phonetic rules. But foreigners have great difficulties to correctly pronounce it. The pronunciation and intonation may change sharply, the result of which is that the pronunciation of the name belongs neither purely to Chinese culture nor purely to English culture. This is a kind of compromise in essence.

There are many channels in intercultural communication. If the structure of language symbolic system is analyzed, we can divide intercultural communication into two types, i.e., intercultural communication in oral way and intercultural communication in written way.

Phonetically, some phonemes in foreign language can neither be heard clearly nor be pronounced correctly, thus posing on great barriers to memorizing them. It is hard for us to memorize a foreigner's name if it is too long and contains too many syllables. It is difficult for us Chinese to memorize a foreign name which has more than four syllables, because our names are usually made up of by two to three syllables. At the same time, it is also uneasy for foreigners to remember our name because the way in which our names are made up of is different from that of theirs. For example, foreigners frequently feel perplexed as to whether or not the family name of “徐俐” is “Xu”. They sometimes made mistakes by taking "Li" as its family. Once the radiobroadcaster of VOA mistook by calling Chinese ambassador to the UN, 黄华, Mr. Hua. Therefore, transliteration is far from enough. And some point out that the more people engaged in intercultural communication have in common, the easier they are able to communicate. For example, it is easier for Chinese people to communicate with Japanese than to communicate with Americans. Because Chinese and Japanese are all familiar with oriental culture and the psychological distance between the two is short.

There are two inclinations concerning the translation of names. One is to translate names in line with the foreign culture and the other is to translate them in accordance with its own culture. Many foreign experts or students in china have their Chinese names. Kevin Polpeter is called “包克文”. Halliday is “韩礼德”。And we are all familiar with the Canadian “大山”, but few can tell his original English name. The same is true when we Chinese live in foreign counties. Many Chinese entitle themselves with English names. 李登科 is called Timothy Lee and 程国宏 is Henry Cheng etc. Some people center their own culture when dealing with the translation of foreign names. It is commonplace for the foreign teachers to give their Chinese students foreign names. They call students whose family name is 王 King and 紹 安 Shean, or they call them Tom, David or Chris directly.

Regarding the translation of foreign names, the common practice in China is to translate them into names of Chinese characteristics. For example, Scarlett O'Hara in Gone With The Wind, is translated into “郝思嘉” and John Leighton Stuart is turned into 司徒雷登. And we often call the world-renowned playwright Shakespeare 莎翁 in Chinese.

To sum up, names are not simple symbols, but rather, they are loaded with abundant cultural and traditional information. In intercultural communication, it is of paramount importance to reach consensus about how to translate participants' names.

\section{COMPARISON OF ADDRESSING BETWEEN CHINESE AND ENGLISH}

As we have had knowledge of the translation of names in intercultural communication, we start turning to touch on another topic which is closely related to the previous one, i.e., the comparison of addressing between Chinese and people from English-speaking countries.

Generally speaking, there are a lot of ways for people to address each other. People can address others by their full names. But in this part of the article, I will center my discussion on the phenomenon that people address others by their first names.

It is easy to understand that the forms of first naming address between Chinese and people from English-speaking countries are different because of the two different cultures. Obviously, we Chinese have more ways in first naming address than westerners do. Following are some forms of first naming in western counties, especially in the U.S. and UK.

First, westerners address each other by one-word first name, e.g., John, Bill, Jane

Second, they address each other by their compound first name, e.g., Mary-Jean

Third, they address each other by their endearment first name, e.g., Dick for Richard, Liz for Elizabeth, and Jim for James etc.

Fourth, they address each other by their generic first name, e.g., Jack, Mack, Buddy etc.

Fifth, they address each other by their nickname, e.g., Short for a tall man, Happy for a person who always smiles, Carrot for a red-haired man etc.

The frequencies of the above five addressing forms by first name are not the same in actual daily use. The first and the third are most frequently used ones. The fourth type is used when people do not know each others' first names. In contrast, there are more forms of first naming in Chinese.

First, Chinese address each other by one-character first name, e.g., Wei (伟), Ze (泽), Li (丽) etc.

Second, Chinese address each other by two-character first name, e.g., Xuefeng (雪峰), Yimiao (毅苗)etc.

Third, Chinese address each other by one-character first name plus er (儿), e.g., Jinger (婧儿), Ronger (蓉儿), Qinger (晴儿)etc. 
Fourth, Chinese address each other with two-character first name out of the duplication of a one-character first name, e.g., Weiwei-Wei (薇薇—薇), Lili-Li (丽丽—丽), Dongdong-Dong (东东一东), etc.

Fifth, Chinese address each other with two-character first name made by put A before the one-character first name, e.g., A-jun (阿军), A-ren (阿仁), A-hua (阿华) etc.

Sixth, Chinese address each other with two-character first name made by put Xiao before the one-character first name, e.g., Xiaoli (小莉), Xiaoshan (小山), Xiaohong (小红) etc.

Seventh, Chinese address each other by two-character surname used as first name, e.g, Duanmu (端木), Ouyang (欧 阳), Situ (司徒) etc.

Eighth, Chinese call children by their infant name, e.g., Laifu (来福), Maomao (毛毛), Guyu (谷雨) etc.

Tenth, Chinese address each other by their nickname, e.g., Dabao (大宝), Baimaoer (白毛儿) etc.

Among these addressing means, we Chinese frequently use the first, second and fourth ones. The fifth one is usually employed in the southern areas of China. The infant name addressing is mainly found in rural areas before a child grows up. The nickname is restricted to close friends.

In western world, the use of first name addressing is conditioned by a few factors such as age, gender, occupation, social and economic status etc. But roughly speaking, westerners tend to use first name when they meet. If they do not know others' names, they would employ generic first names such as Mack, Jack and Buddy. If two adults are introduced to each other, they are likely to be addressed with their titles and last names. But intimacy should be developed before first names are displaced.

There are also conditions where people employ nonreciprocal patterns. These happen when the two parties are not in the same or similar conditions. For instance, children often address adults as Mr. or Mrs. and the latter always call them by their first names. In the meantime, adults address people years their senior with the title and last name, but they themselves are addressed with first name by their peers. And these asymmetrical address patterns may also happen between master and servant, officer and soldier, boss and employee, or teacher and student. Often the superiors can first name the inferiors but the latter cannot do in return. For example, an officer who is younger than his soldiers can address them by their first names but those soldiers, though older than the officer, cannot address him by his first name.

In China, situations here are much the same. In Chinese families, for the sake of solidarity, family members can first name each other. Kin, including husband and wife, brothers, sisters, cousins, and so on, can first name each other provided their age gap is not great. Close friends, colleagues, boy friends and girl friends, and lovers can also conduct the practice. What is noteworthy here is that age difference plays an important role in reciprocity of first naming. Elders in a family, such as grandparents, are able to first name their family members but younger generation cannot do this in return.

Furthermore, Chinese first names can be followed by other addressing forms, which is less in English-speaking countries. Following are some examples.

1. first name + Xiansheng

Wulong Xiansheng

2. first name + tongzhi

Mingfei tongzhi

Comrade Mingfei

3. first name $+\mathrm{jie} / \mathrm{mei}$

Yun Jie

Elder Sister Yun

\section{CONCLUSION}

Translation of names and proper addressing are of paramount importance in intercultural communication. To a great extent, they are the precondition for smooth intercultural communication. As language learners, it poses on lots of requirements for us to grasp the gist of the translation of names and proper addressing means. Only when we are aware of the differences between two cultures can we carry on intercultural communication smooth.

\section{REFERENCES}

[1] Larry A. Samovar, Richard E. Porter \& Lisa A. Stefani. (1998). Communication between cultures. Brooks/Cole/Thomas learning Asia.

[2] Guoming, Chen. (2009). Foundation of Intercultural Communication. East China Normal University Press.

[3] Wenzhong, Hu (1999).Intercultural communication. Foreign Language Teaching and Research Press.

[4] Huaying, Liao.(2010).Case study in intercultural communication. Beijing Institute of Technology Press.

[5] Weiling,Dou.(2007).Fundamentals of intercultural communication. University of International Business and Economics Press.

[6] Linell Davis. (2010) Cross-cultural communication in action. Foreign Language Teaching and Research Press. 
Xueqing Wang was born in Zhenjiang, China in 1980. She received her M.A. degree in Foreign Linguistics and Applied Linguistics, Guangxi Normal University, China in 2009.

She is currently a lecturer in Department of Fundamental Course, Zhenjiang Watercraft College of PLA, Zhenjiang, China. Her research interests include Intercultural communication; Second Language Acquisition and Foreign Language Teaching. 